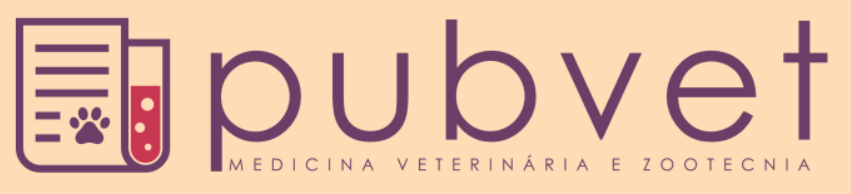

HTTP://DX.DOI.ORG/10.22256/PUBVET.V11N12.1188-1195

\title{
Morfologia de testículos da tuvira (Gymnotus spp.) submetida à reprodução por diferentes protocolos hormonais
}

\author{
Roberta Martins Rosa ${ }^{1}$, Cristielle Nunes Souto ${ }^{2 *}$, Vinícius Santana mota ${ }^{3}$, Jessica Meireles \\ Souza Cunha ${ }^{3}$, Delma Machado Cantisani Padua ${ }^{3}$, Camila Mariangela Pacheco ${ }^{4}$
}

${ }^{1}$ Instituto Federal Goiano, Campus Morrinhos, Rodovia BR 153, KM633 - Zona Rural, Morrinhos - GO, 75650-000

${ }^{2}$ Universidade Federal de Goiás - Regional Jataí, Rod BR 364 KM 192 - Setor Parque Industrial, Jataí- GO, 75801-615

${ }^{3}$ Pontifícia Universidade Católica de Goiás, Avenida Engler, 507 - Jardim Marlisa, Goiânia - GO, 74885-460

${ }^{4}$ Universidade Estadual de Minas Gerais, Divinópolis/MG

*Autor para correspondência: cristielle_nunes@hotmail.com

RESUMO. O objetivo deste trabalho foi analisar a morfologia dos testículos de tuviras machos (Gymnotus spp.) submetidas à reprodução por diferentes indutores hormonais. Foram utilizados quarenta tuviras machos de aproximadamente $40 \pm 5,0 \mathrm{~g} \mathrm{em} \mathrm{um}$ delineamento inteiramente casualizado, com quatro tratamentos e 10 repetições, sendo que cada animal foi considerado uma repetição. Para estabelecimento do protocolo hormonal foram testados três indutores: extrato bruto de hipófise de carpa (EBHC), gonadotrofina coriônica equina (ECG), análogo sintético do hormônio liberador de gonadotrofina ( $\mathrm{GnRH}$ a) e no grupo controle foi administrada solução salina a $2 \%$. Os três hormônios e o controle foram aplicados em duas dosagens (preparatória e indução final). Após 12 horas da segunda aplicação, cinco machos de cada tratamento foram eutanasiados para avaliação macroscópica e microscópica. Foi determinada a proporção volumétrica ocupada pelos componentes do parênquima testicular (túbulos seminíferos e tecido intertubular) e quantificadas as populações de espermatogônias do tipo A, do tipo B, espermatócitos primários, espermatócitos secundários, espermátides, células de Sertoli (S) e proporção de Lúmen. Os resultados indicaram que o hormônio GnRH-a apresentou uma maior capacidade para promover a maturação final nos testículos $(\mathrm{P}<0,05)$, seguido pelo hormônio eCG. O hormônio EBHC não conseguiu promover a maturação final nas tuviras induzidas.

Palavras chave: espermatogônias, GnRH-a, eCG, EBHC, histologia

\section{Testicular morphology of tuvira (Gymnotus spp.) submitted to reproduction by different hormones inducers}

ABSTRACT. The aim of study was to analyze the testis morphology of males tuviras (Gymnotus spp.) submitted to reproduction by different hormonal inducers. Forty male tuviras $(40 \mathrm{~g} \pm 5.0)$ were used approximately in a completely randomized design with four treatments and 10 replicates; each animal was considered a repetition. For hormonal protocol establishment were tested three inducers: crude extract of carp pituitary (EBHC), equine chorionic gonadotropin (ECG), synthetic analogue of gonadotropin-releasing hormone $(\mathrm{GnRH}-\mathrm{a})$ and the control group was administered saline solution at $2 \%$. The three hormones and control were applied in two doses (preparatory and final induction). Ten males per treatment were euthanized for macroscopic and microscopic analysis. It was determined volumetric proportion occupied by the components of testicular parenchyma (seminiferous tubules and intertubular tissue) and quantified populations of spermatogonia type A, type B, primary spermatocytes, secondary spermatocytes, spermatids, Sertoli cells (S) and lumen measurement. The results indicated that the hormone GnRH-a showed a 
higher capacity to promote the final maturation of the testes $(\mathrm{P}<0.05)$, followed by eCG hormone. The EBHC hormone failed to promote the final maturation in males tuviras.

Keywords: spermatogonia, GnRH-and eCG, EBHC, Histology

\section{Morfología de testículos de la Anguilla (Gymnotus spp.) sometida a reproducción por diferentes protocolos hormonales}

RESUMEN. El objetivo de este trabajo fue analizar la morfología de los testículos de Anguillas machos (Gymnotus spp.) Sometidos a la reproducción por diferentes inductores hormonales. Se utilizaron cuarenta Anguilla macho de aproximadamente $40 \pm 5,0 \mathrm{~g}$ en un delineamiento completamente casualizado, con cuatro tratamientos y 10 repeticiones, siendo que cada animal fue considerado una repetición. Para el establecimiento del protocolo hormonal se probaron tres inductores: extracto bruto de hipófisis de carpa (EBHC), gonadotropina coriónica equina (ECG), análogo sintético de la hormona liberadora de gonadotropina (GnRH-a) y en el grupo control se administró solución salina al 2\%. Las tres hormonas y el control se aplicaron en dos dosis (preparatoria e inducción final). Después de 12 horas de la segunda aplicación, cinco machos de cada tratamiento fueron eutanasiados para evaluación macroscópica y microscópica. Se determinó la proporción volumétrica ocupada por los componentes del parénquima testicular (túbulos seminíferos y tejido intertubular) y cuantificadas las poblaciones de espermatogonias del tipo A, del tipo B, espermatocitos primarios, espermatocitos secundarios, espermátides, células de Sertoli (S) y proporción de Lumen . Los resultados indicaron que la hormona GnRH-a presentó una mayor capacidad para promover la maduración final en los testículos (P <0,05), seguido por la hormona eCG. La hormona EBHC no pudo promover la maduración final en las vértigos inducidos.

Palabras clave: espermatogonias, GnRH-a, eCG, EBHC, histología

\section{Introdução}

A tuvira, conhecida também como peixe espada, sarapó, carapó, enguia e ituí, pertencem ao gênero Gymnotus sp., sendo peixes de porte médio, corpo alto e comprido, nadadeira anal longa, ânus e papila urogenital próximas da base do opérculo (Rotta, 2004).

A tuvira tem sido utilizada como isca por pescadores profissionais, artesanais e esportivos em atividades de pesca, sendo um dos peixes mais procurados em comércios de iscas vivas. A captura desse peixe é feita na natureza, e ainda é desconhecida sua reprodução em cativeiro. Esse fato ameaça as populações de tuviras na natureza, podendo acarretar em exaustão dos estoques naturais. Assim, é importante o conhecimento da reprodução artificial dessa espécie, favorecendo o repovoamento em áreas excessivamente exploradas e preservação do habitat e posterior cultivo em cativeiro.

Estudos sobre a biologia reprodutiva de Gymnotus vêm sendo realizados nos últimos anos (Rotta, 2004, Cognato and Fialho, 2006, França et al., 2010). Todavia, não há relatos de estudos envolvendo a criação de tuviras em cativeiro seguida de reprodução artificial. Em cativeiro a maioria dos peixes atinge à maturidade sexual, entretanto, não há todos os estímulos necessários para a maturação final das gônadas, não ocorrendo a desova (Andrade et al., 2015). A indução hormonal utilizando substâncias análogas aos hormônios naturais de peixes constitui uma excelente ferramenta na reprodução de peixes, principalmente se associada à manipulação ambiental (Nagahama and Yamashita, 2008). A associação de técnicas de manipulação ambiental com a indução hormonal utilizando substâncias análogas aos hormônios naturais de peixes constitui uma excelente ferramenta na reprodução de peixes, principalmente se associada à manipulação ambiental. $\mathrm{O}$ extrato bruto de hipófise de carpa (EBHC), a gonadotrofina coriônica equina (eCG) e análogos sintéticos do hormônio liberador de gonadotrofina $(\mathrm{GnRH})$ são indutores hormonais frequentemente utilizados na reprodução artificial de peixes (Zaniboni Filho and Weingartner, 2007). Suas respostas já foram testadas para algumas espécies de peixes (Zaniboni Filho and Campos, 1996, Zaniboni Filho and Weingartner, 2007), causando efeitos positivos da sua utilização. Sendo assim, o presente trabalho objetiva avaliar a resposta 
espermatogênica de tuviras submetidas a diferentes protocolos de indução hormonal.

\section{Material e Métodos}

Essa pesquisa foi conduzida no setor de piscicultura da Pontifícia Universidade Católica de Goiás campus II, seguindo as normas propostas pelo comitê de ética e bem estar animal do Instituto Federal Goiano (protocolo de $\mathrm{n}^{\mathrm{o}}$ 8277040316).

\section{Delineamento e condições experimentais}

Foram utilizadas 40 tuviras machos Gymnotus sp. (40 g $\pm 10 \mathrm{~g})$, oriundas de estabelecimento comercial do município de Goiânia, em um delineamento inteiramente casualizado com três tratamentos (extrato bruto de hipófise de carpa EBHC; gonadotropina coriônica equina - ECG e análogo sintético do hormônio liberador de gonadotrofina - GnRH-a) e dez repetições, sendo cada animal considerado uma repetição. Para o grupo controle foi utilizado solução salina a $2 \%$. $\mathrm{Na}$ manutenção dos animais foram utilizadas quatro caixas de água contendo aproximadamente 400L, dotadas de um sistema air lifting, aquecidas termostaticamente e com aeração constante por pedras porosas acopladas a sopradores.

As determinações de temperatura oxigênio dissolvido, $\mathrm{pH}$, condutividade e amônia foram realizadas diariamente utilizando reagentes padronizados para análises da água. A alimentação foi realizada uma vez ao dia, utilizando-se uma massa homogênea contendo filé de tilápia e gelatina sem sabor. Foram fornecidos $3 \%$ da biomassa, uma vez por dia ad libitum. É importante ressaltar que ainda não é conhecida a exigência nutricional para a espécie em questão e os animais não se adaptaram a ração comercial.

Para indução da espermatogênese da tuvira foram testados três hormônios: o extrato bruto de hipófise de carpa - EBHC, a gonadotropina coriônica equina - ECG e análogo sintético do hormônio liberador de gonadotrofina - GnRH-a. Os três hormônios foram aplicados em duas dosagens, sendo a primeira (preparatória) com a finalidade de promover a maturação final dos gametas e a segunda objetivando a espermiação. Para o grupo controle foi utilizado solução salina a $2 \%$. A aplicação foi realizada utilizando uma seringa de $1 \mathrm{~mL}$, na musculatura dorsal anterior. $\mathrm{O}$ intervalo entre a primeira e segunda aplicação, para todos os tratamentos, foi de 12 horas.
Para a aplicação do extrato bruto de hipófise de carpa (EBHC) foi utilizado a dosagem de 0,5 $\mathrm{mg} / \mathrm{kg}$ na $1^{\mathrm{a}}$ dose e $5,0 \mathrm{mg} / \mathrm{kg}$ na $2^{\mathrm{a}}$ dose (Andrade and Yasui, 2003). A aplicação do análogo sintético do hormônio liberador de gonadotrofina (diacetato tetrahidratado de gonadorelina) foi utilizada nas dosagens de $10 \mathrm{mcg}$ e $100 \mathrm{mcg}$, sendo a primeira e a segunda aplicação, respectivamente (Andrade et al., 2015). A aplicação da gonadotropina coriônica equina (Sincro eCG®) foi administrada nas dosagens de 500 UI na primeira e segunda aplicação. A diluição foi realizada em solução diluente fornecida e prescrita pelo laboratório de fabricação. É importante ressaltar que não há informações sobre a recomendação da dosagem utilizada na indução dessa espécie, por isso foi utilizada uma dosagem que já foi comprovada para machos e fêmeas de outras espécies de peixes (Zaniboni Filho and Weingartner, 2007). Para as análises histológicas, foram eutanasiados os 10 machos de cada tratamento, por incisão e ruptura da medula dorsal após prévia desensibilização em água com gelo. A hora grau de extrusão estipulada para o presente estudo foi de 250 horas graus, baseada em uma média para peixes de clima tropical. Para tuviras, não foi encontrado até a presente pesquisa estudos determinando sua hora grau.

Após eutanásia, os testículos foram avaliados e retirados pela secção ventral da cavidade celomática. Para descrição microscópica dos testículos e descrição dos tipos celulares dos diferentes tratamentos, os tecidos gonadais dos machos foram fixados em solução de Bouin por 24 horas. Posteriormente foram armazenados em álcool $70 \%$, confeccionadas as lâminas de microscopia e analisados segundo protocolo de Cognato and Fialho (2006).

O software Image-Pro Plus ${ }^{\circledR}$ foi utilizado para verificar a proporção volumétrica ocupada pelos componentes do parênquima testicular (túbulos seminíferos e tecido intertubular). Uma grade quadrangular é sobreposta as imagens facilitando a contagem de 2660 pontos projetados sobre cada foto das lâminas histológicas.

Para cada intersecção de uma linha horizontal com uma linha vertical, determina-se um ponto a ser analisado, quantificando-se assim o percentual de pontos sobre túbulos seminíferos (túnica própria, epitélio seminífero e lúmen) e intertúbulo. Foi quantificada a proporção das populações de espermatogônias do tipo A, do tipo B, 
espermatócitos primários, espermatócitos secundários, espermátides e células de Sertoli (S). Foram quantificados dez campos microscópicos por animais.

Os resultados obtidos foram submetidos a Análise de variância (ANOVA) e quando significativos foram analisados pela comparação de médias utilizando o teste de Tukey, executado pelo software Statistical Analysis Sistem - SAS 9.0.

\section{Resultados e discussão}

\section{Características anatômicas}

Em todos os tratamentos os peixes foram eutanasiados e os testículos observados. Peixes induzidos e peixes do grupo controle apresentaram testículos ovais de coloração amareloesbranquiçadas. Foram identificados testículos em pares, consistentes, localizados ventralmente na cavidade celomática entre a extremidade cranial da bexiga natatória e a extremidade caudal do conjunto visceral (Figura 1). Os ductos espermáticos apresentaram-se ovais e pares, emergindo na região cranial dos testículos e finalizando-se na papila urogenital, localizada abaixo da cabeça, ao lado do ânus, próxima a base do opérculo.

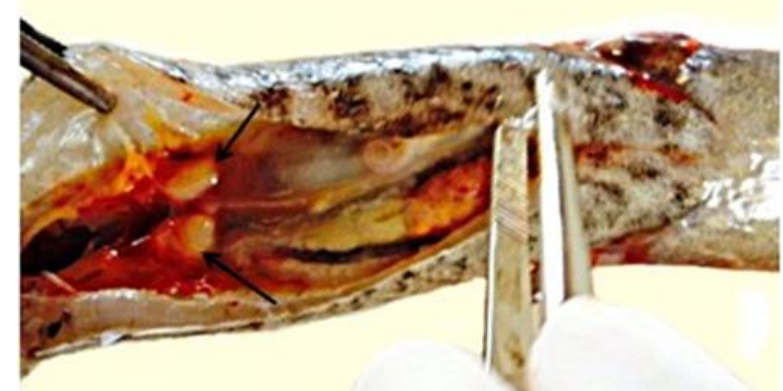

Figura 1. Interior da cavidade celomática de uma tuvira evidenciando os testículos (T) ovais de coloração amarelo esbranquiçadas, localizados ventralmente (seta). Fonte: Arquivo pessoal

\section{Características histológicas}

$\mathrm{Na}$ análise histológica das lâminas de todos os tratamentos, foram observadas características comuns aos peixes do gênero Gymnotus, como testículos envoltos pela túnica albugínea que se apresentava composta por uma rede de fibras conectivas que invaginavam no interior do órgão, no tecido intersticial, delimitando e sustentando os túbulos seminíferos. Os testículos foram classificados quanto à estrutura como tubular anastomosado, com regiões tubulares e intertubulares. $\mathrm{Na}$ região intertubular foram observadas células de Leydig, mióides, entre outras, enquanto na região tubular foram observadas células da linhagem germinativa (espermatogônia A, espermatogônia B, espermatócito primário, espermatócito secundário, espermátide e espermatozoide) e células de Sertoli. Entre essas regiões encontra-se o epitélio germinativo, responsável pelas delimitações das mesmas.

Foi observado em todos os peixes o testículo do tipo tubular anastomosado (Figura 2). Cognato and Fialho (2006) e França et al. (2010) encontraram estrutura testicular semelhante em estudos com Gymnotus spp. e Gymnotus carapo. Vergílio et al. (2013) analisando testículo maduros de Gymnotus carapo observaram a presença de testículos lobulares irrestritos (onde as espermatogônias foram observadas ao longo do túbulo). Apesar de a classificação diferir do encontrado na pesquisa, o autor mencionou na presença de anastomoses no testículo do tipo lobular.

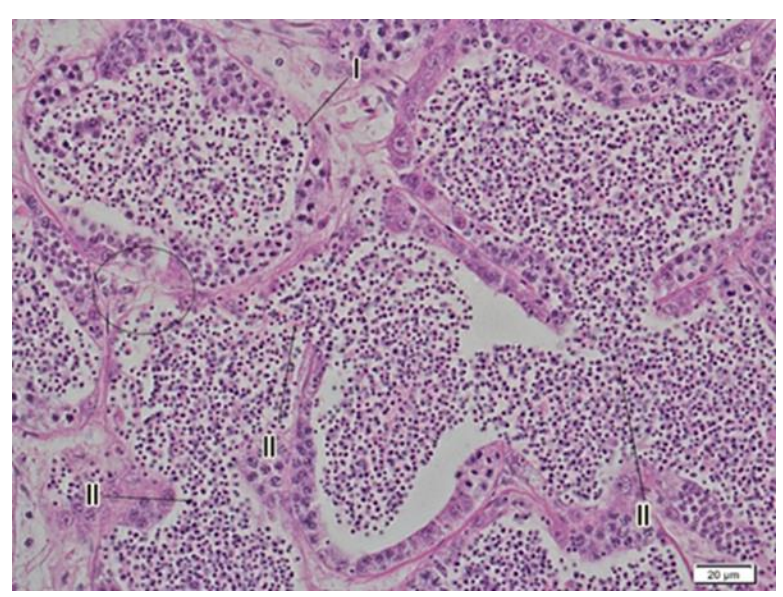

Figura 2. Corte histológico do testículo de tuvira induzida por $\mathrm{GnRH}$ indicando a presença de túbulos anastomosados (II) e um túbulo íntegro (I) iniciando processo de anastomose (região em evidencia). Fonte: Arquivo pessoal

Com auxílio de microscopia óptica foram identificadas seis diferentes tipos de células germinativas para todos os grupos de animais estudados: espermatogônias primárias, espermatogônias secundárias, espermatócitos primários, espermatócitos secundários, espermátides e espermatozoides (Tabela 1).

As espermatogônias A, ou primárias representam as células germinativas precursoras. 
Quando comparado todos os tratamentos, o grupo controle apresentou médias significativamente superiores $(\mathrm{P}>0,05)$ em relação aos demais tratamentos (Tabela 1). França et al. (2010) ao trabalhar com Gymnotus sp. determinou cinco fases reprodutivas: regressão, maturação inicial, maturação intermediária, maturação final e regredida. Segundo a autora, os cistos de espermatogônias A tendem aumentar à medida que os peixes se afastam da fase de maturação final, justificando a maior presença de espermatogônias primárias no grupo não induzido, i. é., tratamento controle. Os tratamentos com indutores hormonais não apresentaram diferenças significativas entre si.

Tabela 1. Médias das proporções (\%) das células da linhagem espermatogênica, Sertoli e Lúmen testicular de tuviras submetidas à indução por diferentes hormônios.

\begin{tabular}{lccccccc}
\hline Tratamento & Esp.A & Esp. B & Esp. I & Esp. II & Emi. & Sertoli & Lúmen \\
\hline Controle & $8.480 \mathrm{a}$ & $7.242 \mathrm{a}$ & $7.220 \mathrm{a}$ & $7.580 \mathrm{~b}$ & $5.460 \mathrm{c}$ & $53.200 \mathrm{a}$ & $9.344 \mathrm{a}$ \\
EBHC & $4.100 \mathrm{~b}$ & $8.724 \mathrm{a}$ & $6.280 \mathrm{a}$ & $11.500 \mathrm{a}$ & $4.880 \mathrm{c}$ & $41.200 \mathrm{ab}$ & $8.236 \mathrm{a}$ \\
$\mathrm{eCG}$ & $3.700 \mathrm{~b}$ & $7.966 \mathrm{a}$ & $2.700 \mathrm{~b}$ & $2.880 \mathrm{c}$ & $12.020 \mathrm{~b}$ & $37.800 \mathrm{~b}$ & $11.218 \mathrm{a}$ \\
$\mathrm{GnrH}$ & $2.060 \mathrm{~b}$ & $69.42 \mathrm{a}$ & $1.960 \mathrm{~b}$ & $4.480 \mathrm{bc}$ & $19.440 \mathrm{a}$ & $37.800 \mathrm{~b}$ & $12.190 \mathrm{a}$ \\
\hline CV\% & 15,95 & 26,32 & 29,76 & 26,36 & 19,41 & 11,94 & 24,10 \\
\hline
\end{tabular}

Esp.A= Espermatogônia A; Esp.B = Espermatogônia B; Esp.I = Espermatócito primário; Esp.II = Espermatócito secundário; Emi=Espermátide; $C V$ = Coeficiente de variação. Médias seguidas pela mesma letra não diferem entre si pelo teste de Tukey. Médias seguidas por letras diferentes diferem pelo teste de Tukey $(\mathrm{P}<0,05)$.

As espermatogônias A apresentaram maior tamanho em relação às demais células germinativas. Foram encontradas tanto isoladas como aos pares na parede dos túbulos seminíferos apresentando núcleo grande, esférico, localizado na região central do citoplasma, o citoplasma apresentou-se claro e abundante, cujo limite foi dificilmente notado na microscopia de luz. Resultados semelhantes foram encontrados para diversos estudos com tuviras (Cognato and Fialho, 2006, França et al., 2010, Vergílio et al., 2013).

Schulz et al. (2010) denominaram espermatogônias A solteiras, como espermatogônias A indiferenciadas enquanto as células encontradas em pares foram denominadas de espermatogônias A diferenciadas. Os autores mencionaram que o potencial de auto renovação diminui com a divisão mitótica, ficando este maior nas espermatogônias A indiferenciadas.

As divisões mitóticas das espermatogônias A originam as espermatogônias $\mathrm{B}$, ou secundárias. Os cortes histológicos de tuviras induzidas e do grupo controle não apresentaram diferenças quanto à quantidade de espermatogônias $\mathrm{B}$ (Tabela 1). Na maturação intermediária, as quantidades de espermatogônias B aumentam enquanto as quantidades de espermatogônias $\mathrm{A}$ diminuem. Gônadas que alcançam a maturação final apresentam menores quantidades de espermatogônias primárias e secundárias (França et al., 2010). Os resultados encontrados por França et al. (2010) não corroboram com o resultado encontrado na presente pesquisa, fazendo-se necessário mais estudos quanto a este tipo celular. Em todos os tratamentos foram observados espermatogônias B em diversas fases da divisão mitótica. Schulz and Miura (2002) e Schulz et al. (2010) mencionam em seus estudos que espermatogônias secundárias sofrem várias divisões mitóticas, originando gerações de espermatogônias B.

A quantidade de as espermatogônias divisões mitóticas das espermatogônias secundárias em tuviras, ainda não foi relatada até a data da presente pesquisa. Estudos em alguns peixes já são mencionados, como nos peixes mosquito (Gambusia affinis), em que foram observadas de dez a doze divisões mitóticas e na truta-arco-íris (Oncorhynchus mykiss) em que foram observadas seis divisões das espermatogônias B (Grier, 1993, Loir, 1999, Grier and Uribe-Aranzábal, 2009).

Foi observado nos cortes histológicos dos testículos de todos os tratamentos espermatogônias B menores, quando comparadas as espermatogônias primárias, de núcleo grande e delimitação citoplasmática pouco evidente. Para estas células, os tratamentos induzidos com os hormônios eCG e o GnRH-a apresentaram diferenças do tratamento controle em relação aos peixes induzidos com EBHC $(\mathrm{P}<0,05)$. Os peixes induzidos com eCG e GnRH-a, apresentaram as médias menores e não apresentaram diferenças significativas entre si. O EBHC, assim como o grupo controle não se diferiram entre si e apresentaram as maiores médias (Tabela 1). Números menores de espermatócitos primários no 
grupo controle em relação so tratamentos hormonais com eCG e GnRH-a sugerem um estágio de maturação gonadal mais avançado para estes testículos, que pode ser justificado pela diferenciação destes espermatócitos primários em secundários e consequentemente em espermátides. França et al. (2010) ao classificar as fases reprodutivas de machos Gymnotus sp. caracterizaram as fases de maturação final como uma fase de menor quantidade de espermatócitos primários e secundários. Observou-se que os espermatócitos primários encontraram-se agrupados formando cistos, com formato regular, citoplasma hialino e escasso, quase totalmente ocupado por um núcleo central e esférico. Apresentaram diâmetro celular bem menor que as espermatogônias B. Não foram encontradas diferenças morfométricas destas células quando comparadas a outros estudos (Cognato and Fialho, 2006, França et al., 2010, Vergílio et al., 2013).

Os cistos de espermatócitos secundários apresentaram diferenças $(\mathrm{P}<0,05)$ do grupo controle para os tratamentos com os hormônios eCG e EBHC, apresentando a menor e maior média respectivamente (Tabela 1). Os animais induzidos com hormônio GnRH-a não apresentaram diferenças $(\mathrm{P}>0,05)$ do grupo controle e dos peixes induzidos com o hormônio eCG. A maior média de espermatócitos secundários para o hormônio EBHC sugere uma maturação gonadal menos avançada em relação aos demais hormônios, visto que os espermatócitos secundários não chegaram à fase de espermátides. Sugere-se que este hormônio exija um período de ação maior que os demais hormônios utilizados na pesquisa.

O tratamento utilizando o hormônio eCG, apresentou média menor quando comparado ao grupo controle, caracterizando a fase de maturação final dos testículos. Os tratamentos com eCG e GnRH-a não diferiram entre si.. Testículos induzidos com GnRH-a não apresentaram diferenças significativas quando comparados ao grupo controle e ao hormônio eCG. Porém pode-se sugerir que este tratamento também se encontra em fase de maturação final, quando considerado os valores apresentados para espermatogônias A e espermátides.

A partir meiose II dos espermatócitos secundários surgem os cistos de espermátides. Para estes cistos os animais induzidos com os hormônios GnRH-a e eCG apresentaram valores diferentes significativamente do grupo controle e entre si $(\mathrm{P}<0,05)$ detendo as maiores médias, respectivamente. $\mathrm{O}$ tratamento com EBHC apresentou testículos com as menores médias para espermátides, não apresentaram diferença do grupo controle, mas se diferenciaram dos demais hormônios (eCG e GnRH-a) $(\mathrm{P}<0,05)$.

As espermátides são células sofre diferenciação para se tonar espermatozoides. Sua presença em grandes quantidades indica a fase de maturação final dos testículos. A presença de maior média destas células para as tuviras induzidas com $\mathrm{GnRH}$, indicam a maior eficiência deste hormônio na indução dos peixes a reprodução. Uma possível explicação para a maior o estágio de espermatogênese avançada do hormônio GnRH-a, seria a ação do LH e do FSH endógenos do peixe. Os receptores de membrana das células de Sertoli e Leydig se ligariam a estas moléculas naturais, gerando uma resposta melhor na indução dos peixes.

Para o tratamento com EBHC o número de células do tipo espermatogônia $B$ e espermátide foram menores em relação aos demais tratamentos e sem diferença para o grupo controle $(P>0,05)$. Tal fato sugere peixes em maturação inicial das gônadas quando associada a alta presença de espermatócitos secundário observado neste estudo (Figura 3). A eficiência reprodutiva deste hormônio quanto ao período de ação sugere um tempo maior.

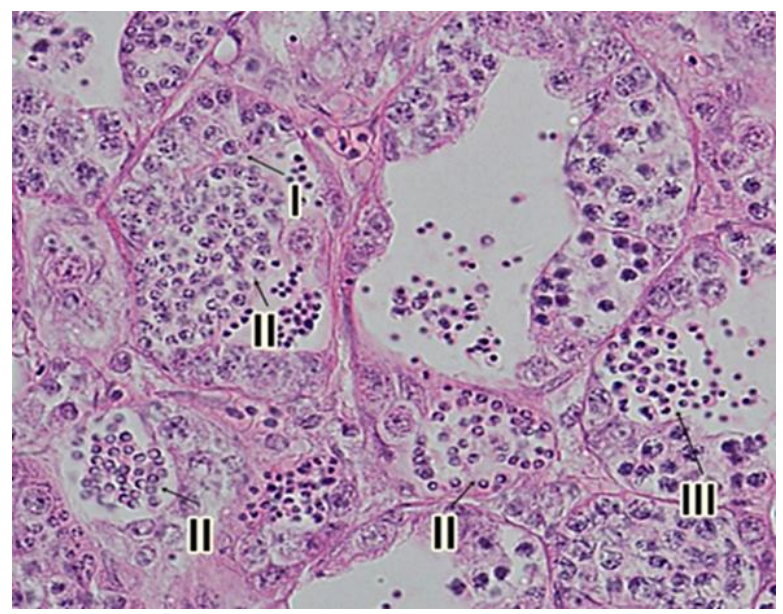

Figura 3. Corte histológico do testículo de tuvira induzida com o hormônio EBHC indicando um cisto de espermatócito primário (I), dois cistos de espermatócitos secundários (II) e um cisto de espermátide (III). Fonte: Arquivo pessoal.

O hormônio eCG, representou o segundo maior número de espermátides. Para os resultados obtidos com os hormônios eCG e EBHC, uma provável explicação seria a menor capacidade destes se ligar nos receptores de membrana das 
células de Sertoli e Leydig, visto que são hormônios originários de espécies diferentes, sendo o primeiro derivado de equinos e o segundo de carpas.

As espermátides se apresentaram como células menores que os espermatócitos secundários e mais abundantes nos cistos germinativos. Apresentam pouca cromatina e estão situadas próximo ao lúmen do túbulo seminífero. Cistos de espermátides foram encontrados íntegros $\mathrm{e}$ rompidos. Em cistos rompidos as espermátides foram encontradas no lúmem tubular, caracterizando a espermatogênese semi-cística.

As células de Sertoli, que determinam a capacidade espermatogênica do testículo, estão envolvidas na nutrição, sustentação, fagocitose e estimulação das células germinativas. Todos os tratamentos com hormônios, exceto o EBHC, apresentaram diferenças significativas de número de células de Sertoli para o grupo controle, que apresentou os maiores números de células (Tabela 1). O hormônio EBHC não apresentou diferença significativa para os demais indutores (eCG e GnRH). A quantidade de células de Sertoli pode ser associada ao número de espermatogônias $\mathrm{A}$ e B . França et al. (2010) e Vergílio et al. (2013) mencionam que, para tuviras, há a presença de um maior número de cistos de espermátides no estágio de maturação final. Os autores mencionados observaram as mesmas estruturas celulares e císticas, colaborando para os resultados encontrados, especialmente para espermatogênese semi-cística. As células de Sertoli foram encontradas na periferia dos túbulos com núcleos evidentes e centralizados, citoplasma bem delimitado e formato triangular, apresentando-se de forma isolada. Schulz et al. (2010) descreveram as mesmas características morfométricas para estas células.

Em mamíferos, as células de Sertoli são constantes, não havendo aumento em seu número durante a espermatogênese. Para peixes há relatos do aumento do número de células de Sertoli de acordo com as divisões mitóticas ou espermatogoniais. A intensidade deste aumento nas células de Sertoli são espécie-específicos e de acordo com a fase reprodutiva dos peixes ( $\underline{\text { Schulz }}$ et al., 2010). No lúmen testicular encontram-se os espermatozoides. Não houve diferenças para nenhum tratamento sobre as médias referentes ao lúmen tubular, porém foi observado diferenças na quantidade de espermatozoides dentro do lúmen (Figura 4). Os hormônios GnRH-a e eCG apresentaram lúmens mais repletos, o tratamento com o hormônio EBHC e o grupo controle apresentaram lúmens com poucas concentrações espermáticas. Tais resultados pontuam novamente para a maturação incompleta dos testículos induzidos com EBHC e a melhor eficiência hormonal dos hormônios GnRH-a e o eCG.

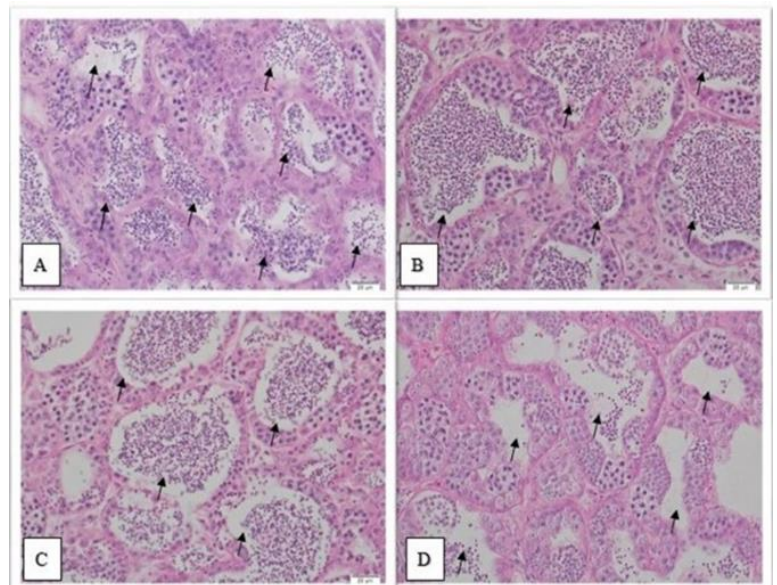

Figura 4. Corte histológico do testículo de tuviras mostrando o lúmen tubular com espermatozoides (setas). A figura A representa o grupo controle, a figura $\mathrm{B}$ representa o grupo induzido com o hormônio GnRH, a figura C representa os animais induzidos com o hormônio eCG e D EHBC. Fonte: Arquivo pessoal.

\section{Conclusão}

De acordo com as análises efetuadas, concluise que o análogo sintético do hormônio liberador de gonadotrofina (GnRH-a) apresentou os melhores resultados na indução hormonal de tuviras, Gymnotus sp.. Maiores pesquisas se fazem necessárias na criação de tuviras em cativeiro visando o conhecimento, a criação e a preservação da espécie.

\section{Referências Bibliográficas}

Andrade, D. R. \& Yasui, G. S. 2003. O manejo da reprodução natural e artificial e sua importância na produção de peixes no Brasil. Revista Brasileira de Reprodução Animal, 27, 166-172.

Andrade, E. S., Andrade, E. A., Felizardo, O. V., Jesus Paula, D. A., Veras, G. C. \& Murgas, L. D. S. 2015. Biologia reprodutiva de peixes de água doce. Revista Brasileira de Reprodução Animal, 39, 195-201.

Cognato, D. P. \& Fialho, C. B. 2006. Reproductive biology of a population of Gymnotus aff. carapo (Teleostei: Gymnotidae) from southern Brazil. Neotropical Ichthyology, 4, 339-348. 
França, G. F., Grier, H. J. \& Quagio-Grassiotto, I. 2010. A new vision of the origin and the oocyte development in the Ostariophysi applied to Gymnotus sylvius (Teleostei: Gymnotiformes). Neotropical Ichthyology, 8, 787-804.

Grier, H. J. 1993. Comparative organization of Sertoli cells including the Sertoli cell barrier. The Sertoli Cell, 1, 703-739.

Grier, H. J. \& Uribe-Aranzábal, M. C. 2009. The testis and spermatogenesis in teleosts. In: Jamieson, B. G. M. (ed.) Reproductive biology and phylogeny of fishes (Agnathans and Bony fishes). Science Publishers.

Loir, M. 1999. Spermatogonia of rainbow trout: II. In vitro study of the influence of pituitary hormones, growth factors and steroids on mitotic activity. Molecular Reproduction and Development, 53, 434-442.

Nagahama, Y. \& Yamashita, M. 2008. Regulation of oocyte maturation in fish. Development, Growth \& Differentiation, 50, 195-219.

Rotta, M. A. 2004. Aspectos biológicos e reprodutivos para a criação da Tuvira (Gymnotus sp.) em cativeiro-I. Embrapa Pantanal-Documentos, 73, 1-16.

Schulz, R. W., França, L. R., Lareyre, J.-J., LeGac, F., Chiarini-Garcia, H., Nobrega, R. H. \&
Miura, T. 2010. Spermatogenesis in fish. General and Comparative Endocrinology, 165, 390-411.

Schulz, R. W. \& Miura, T. 2002. Spermatogenesis and its endocrine regulation. Fish Physiology and Biochemistry, 26, 43-56.

Vergílio, C. S., Moreira, R. V., Carvalho, C. E. V. \& Melo, E. J. T. 2013. Characterization of mature testis and sperm morphology of Gymnotus carapo (Gymnotidae, Teleostei) from the southeast of Brazil. Acta Zoologica, 94, 364-370.

Zaniboni Filho, E. \& Campos, N. D. B. 1996. Priming hormone administration to induce spawning of some Brazilian migratory fish. Revista Brasileira de Biologia, 56, 655-659.

Zaniboni Filho, E. \& Weingartner, M. 2007. Técnicas de indução da reprodução de peixes migradores. Revista Brasileira de Reprodução Animal, 31, 367-373.

\section{Article History:}

Received 3 July 2017

Accepted 8 August 2017

Available on line 14 October 2017

License information: This is an open-access article distributed under the terms of the Creative Commons Attribution License 4.0, which permits unrestricted use, distribution, and reproduction in any medium, provided the original work is properly cited. 